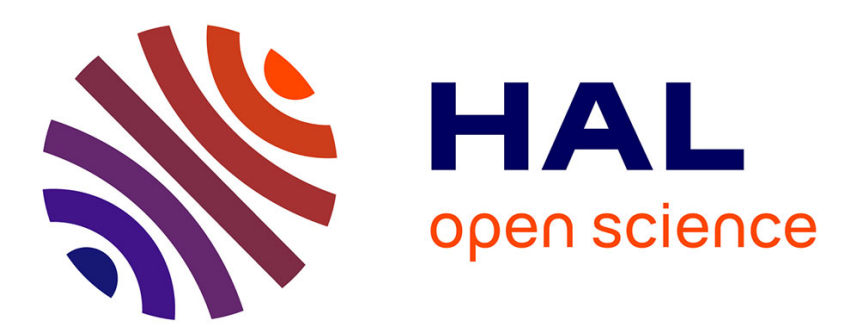

\title{
Simultaneous effects of photo- and radio- darkening in ytterbium-doped aluminosilicate fibers
}

Jean-Bernard Duchez, Franck Mady, Yasmine Mebrouk, Mourad

Benabdesselam

\section{- To cite this version:}

Jean-Bernard Duchez, Franck Mady, Yasmine Mebrouk, Mourad Benabdesselam. Simultaneous effects of photo- and radio- darkening in ytterbium-doped aluminosilicate fibers. AIP Conference Proceedings, 2014, 10.1063/1.4900453 . hal-01223819

\section{HAL Id: hal-01223819 \\ https://hal.science/hal-01223819}

Submitted on 3 Nov 2015

HAL is a multi-disciplinary open access archive for the deposit and dissemination of scientific research documents, whether they are published or not. The documents may come from teaching and research institutions in France or abroad, or from public or private research centers.
L'archive ouverte pluridisciplinaire HAL, est destinée au dépôt et à la diffusion de documents scientifiques de niveau recherche, publiés ou non, émanant des établissements d'enseignement et de recherche français ou étrangers, des laboratoires publics ou privés. 


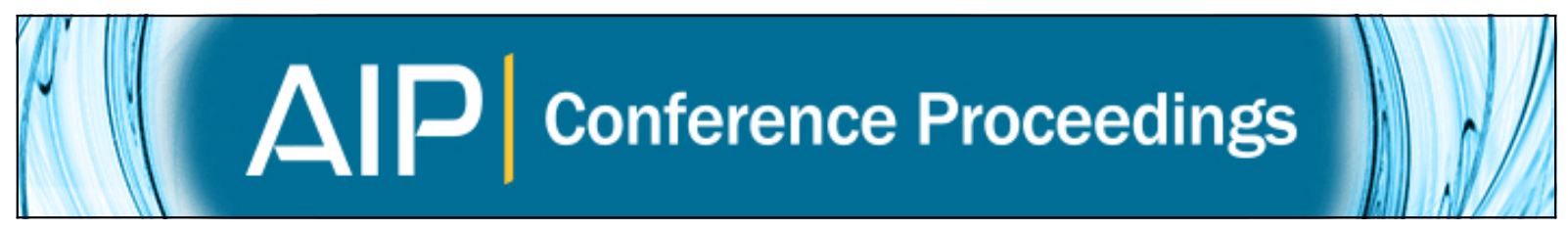

Simultaneous effects of photo- and radio- darkening in ytterbium-doped aluminosilicate fibers

Jean-Bernard Duchez, Franck Mady, Yasmine Mebrouk, and Mourad Benabdesselam

Citation: AIP Conference Proceedings 1624, 31 (2014); doi: 10.1063/1.4900453

View online: http://dx.doi.org/10.1063/1.4900453

View Table of Contents: http://scitation.aip.org/content/aip/proceeding/aipcp/1624?ver=pdfcov

Published by the AIP Publishing

\section{Articles you may be interested in}

Ytterbium-doped solid core photonic bandgap fiber for laser operation around $980 \mathrm{~nm}$

Appl. Phys. Lett. 92, 061113 (2008); 10.1063/1.2857464

Optically induced linear electro-optic effects in ytterbium-doped strontium yttrium borate Sr 3 Y ( B O 3 ) 3 : Yb nanocrystallites incorporated into polymer matrices

Appl. Phys. Lett. 89, 131106 (2006); 10.1063/1.2357035

Electronic structure of ytterbium-doped strontium fluoroapatite: Photoemission and photoabsorption investigation J. Appl. Phys. 91, 5135 (2002); 10.1063/1.1459601

Measurements of optical refrigeration in ytterbium-doped crystals

J. Appl. Phys. 90, 4815 (2001); 10.1063/1.1406544

Simultaneous strain-temperature measurement using fluorescence from Yb-doped silica fiber

Rev. Sci. Instrum. 71, 2267 (2000); 10.1063/1.1150439 


\title{
Simultaneous Effects of Photo- and Radio- Darkening in Ytterbium-Doped Aluminosilicate Fibers
}

\author{
Jean-Bernard Duchez ${ }^{\text {a) }}$, Franck Mady, Yasmine Mebrouk and \\ Mourad Benabdesselam \\ University of Nice Sophia Antipolis, Laboratoire de Physique de la Matière Condensée \\ CNRS UMR 7336, Parc Valrose, 06108 NICE cedex 2, France

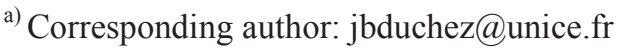

\begin{abstract}
We present original characterizations of photo-radio-darkening in ytterbium-doped silica optical fibers submitted to the simultaneous action of the pump and of an ionizing radiation. We present the interplay between both radiations, showing e.g. that the pump is able to darken or bleach the fiber depending on the ionizing dose. The photoresistance of the fiber is shown to play a crucial role on its radio-resistance, and that photo-resistant fibers should be also radio-resistant in low dose rate conditions. All the results are thoroughly explained by a physical model presented in a separate article by Mady et al. (this conference proceeding).
\end{abstract}

\section{INTRODUCTION}

Ytterbium-doped silica optical fibers (YDF) may suffer from two darkening processes when used under pumping in radiative environments. Excess optical losses are induced by external ionizing radiations (radiodarkening or RD), but also, possibly, due to the pump itself (photo-darkening, PD). PD and RD of YDF have been already well characterized [1-12], but by distinct communities. Possible interplay between PD and RD has neither been characterized nor modelled, though pumping and ionizing radiations should be at play simultaneously in some operation conditions, as in space-based applications. We present an experimental study of simultaneous photo-radiodarkening (PRD). The results show that the PD level is of first importance in the RD resistance. A complementary work by Mady et al., also published in this conference proceeding, presents a model explaining all of the present results.

\section{EXPERIMENTAL METHODS}

The measurement bench is based on a pump-probe scheme [4,7,10] with contra-propagating pump (977 nm, $\sim 230 \mathrm{~mW})$ and visible probe $(633 \mathrm{~nm}$, a few $\mathrm{mW})$. Customized wavelength division multiplexers (OZ-optics) are used for coupling pump and probe lights into the fiber under test (FUT). Two YDF FUTs were compared. One with Aluminium ( $\mathrm{Al}$ ) and Ytterbium (Yb), named $\mathrm{Al}-\mathrm{Yb}\left(0.9 \% \mathrm{Al}_{2} \mathrm{O}_{3}, 0.3 \% \mathrm{Yb}_{2} \mathrm{O}_{3}, \mathrm{NA}=0.11\right)$, fabricated and drawn in our lab. This fiber is not optimized to resist against PD nor RD. The second YDF is a COTS fiber (Component Off the Shelf) containing Al, $\mathrm{Yb}$ and also Cerium (Ce). It is named Al-Yb-Ce $\left(4.8 \% \mathrm{Al}_{2} \mathrm{O}_{3}, 0.4 \% \mathrm{Yb}_{2} \mathrm{O}_{3}, 0.3 \% \mathrm{Ce}_{2} \mathrm{O}_{3}\right.$, $\mathrm{NA}=0.2$ ). This fiber exhibits low PD levels. The FUTs consisted in $\sim 2 \mathrm{~cm}$ long uncoated samples. They were irradiated in-line, under pumping or not, by an X-ray generator $(\mathrm{Cu}$ anode, $45 \mathrm{kV})$. The dose delivered to the sample is measured by an ionizing chamber (PTW 23342 with electrometer UnidosE) placed right under the fiber.

Fundamentals and Applications in Silica and Advanced Dielectrics (SiO2014)

AIP Conf. Proc. 1624, 31-36 (2014); doi: 10.1063/1.4900453

(C) 2014 AIP Publishing LLC 978-0-7354-1261-3/\$30.00 


\section{RESULTS}

The effects of PD and PRD in the Al-Yb sample are shown in Fig. 1. When the FUT is in-core pumped, the pump output power decays due to PD, but the PD level tends to a stable value. Such a PD equilibrium was already observed, carefully examined by Jetschke et al. [4], and shown to be determined by the pump power. Therefore the pump is not only responsible for PD, but also for a photobleaching (PB) effect, which balances PD at long pumping time.

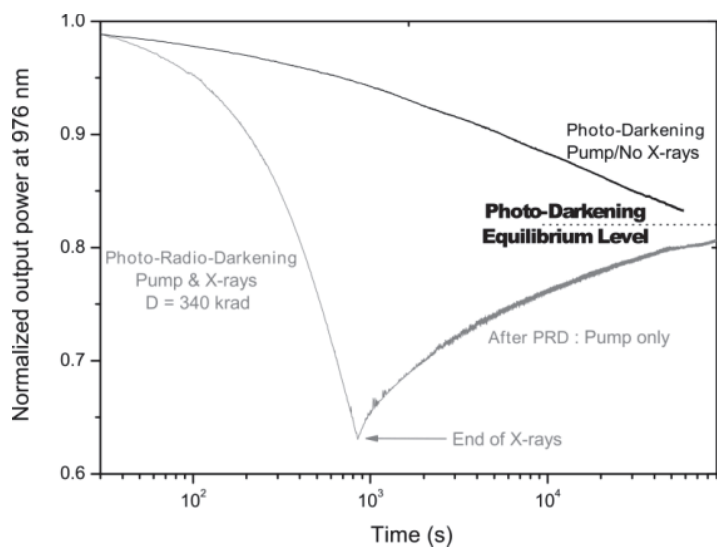

FIGURE 1. Decay of the normalized output power at $977 \mathrm{~nm}$ for the Al-Yb fiber, for pure PD and PRD.

The same $\mathrm{Al}-\mathrm{Yb}$ fiber (fresh sample) was submitted to a PRD run: it was irradiated by X-rays $\left(23 \mathrm{krad}\left(\mathrm{SiO}_{2}\right)\right.$. $\left.\min ^{-1}, 340 \mathrm{krad}\left(\mathrm{SiO}_{2}\right)\right)$ during pumping and then, after the end of the X-ray irradiation, left to the sole action of the pump. During the PRD step, the output power drops rapidly compared to the smooth PD decrease. This drop is therefore markedly dominated by RD. Then the YDF is obviously photo-bleached by the pump: the output power moves back up, tending to the same equilibrium level than pure PD, as shown in Fig. 1. The PRD is also bleached by the pump, so is RD. This demonstrates a basic interplay between PD and RD and highlights the crucial role of the PD equilibrium level (PDEL). It is not surprising that the pump bleaches both PD and RD, because our team already showed that trapped-states responsible for PD and RD in YDF are of the same nature [11]. Similar experiments were done at various doses (Al-Yb, fresh samples). Results are displayed in Fig. 2 for pump and probe wavelengths. For the 2 higher doses, the result is the same as in Fig. 1: PRD followed by pump-induced PB. When X-rays are stopped at $45 \mathrm{krad}$, the output power level is still above the PDEL and the pump is responsible for further degradation, i.e. PD. All plots tend to the PDEL. This convergence seems less clear in Fig. 2 than in Fig. 1 because the time window of Fig. 2 is fifty times smaller than that of Fig. 1 (the 340 krad curve of Fig. 2a is the same as that plotted in Fig. 1). Similar behaviors are always found for the pump and the probe, even if, as usual, degradation is more important in the visible range.

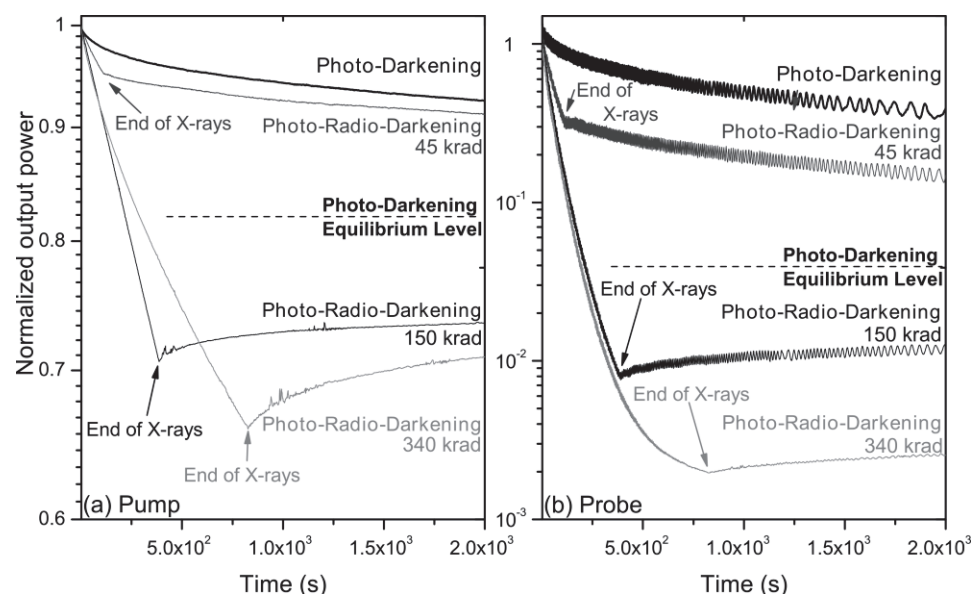

FIGURE 2. PD and PRD of the Al-Yb sample at various doses at $977 \mathrm{~nm}$ (a) and $633 \mathrm{~nm}$ (b). 
According to Fig. 2., the main action of the pump after X-rays depends on the ionizing dose. To highlight the pump effect during X-ray irradiation, same doses were given to $\mathrm{Al}-\mathrm{Yb}$ and $\mathrm{Al}-\mathrm{Yb}$-Ce fibers with and without pumping during X-ray irradiation (PRD and RD conditions respectively). Results are shown in Fig. 3, now in terms of the excess absorption factor $\Delta \alpha$ (in cm-1) calculated using equation (1):

$$
\Delta \alpha(t)=-\frac{1}{L} \times \ln \left(\frac{P_{\text {in }}(0)}{P_{\text {out }}(0)} \times \frac{P_{\text {out }}(t)}{P_{\text {in }}(t)}\right)
$$

Where $L$ is the length of the FUT, $P$ in $(t)$ is the input power at $976 \mathrm{~nm}$ which is almost a constant equal to $\operatorname{Pin}(0)$, and $P$ out $(t)$ the output power at $976 \mathrm{~nm}$. Two doses have been imparted: one is small $(30 \mathrm{krad})$ to keep the radio-induced degradation below the PDEL, the other is high $(450 \mathrm{krad})$ to exceed this level. At the same pump input power the Al-Yb-Ce fiber has a much lower PDEL than our Al-Yb fiber. It is also found to present a better Xray resistance (the 2 fibers show RD or PRD levels in similar proportion with respect to their PDEL). At low dose, below the PDEL, both fibers are less darkened in RD than in PRD conditions. Then, the pump accelerates degradation. For the dose above the PDEL, PRD is less pronounced than $\mathrm{RD}$, so the degradation is slowed down by the pump. Hence the effect of the pump during and after PRD is the same: PD or PB, depending on the imparted ionizing dose. Because of its $\mathrm{PB}$ action, the pump mitigates $\mathrm{RD}$ at high doses. As shown by the measurements of Fig. 4., the PRD will also reach a stationary state above the PDEL at long irradiation time, thus freezing the PRD level despite the continuous irradiation. This PRD level is called Photo-Radio-Darkening Equilibrium Level (PRDEL) and it sets the worst degradation level in PRD conditions.
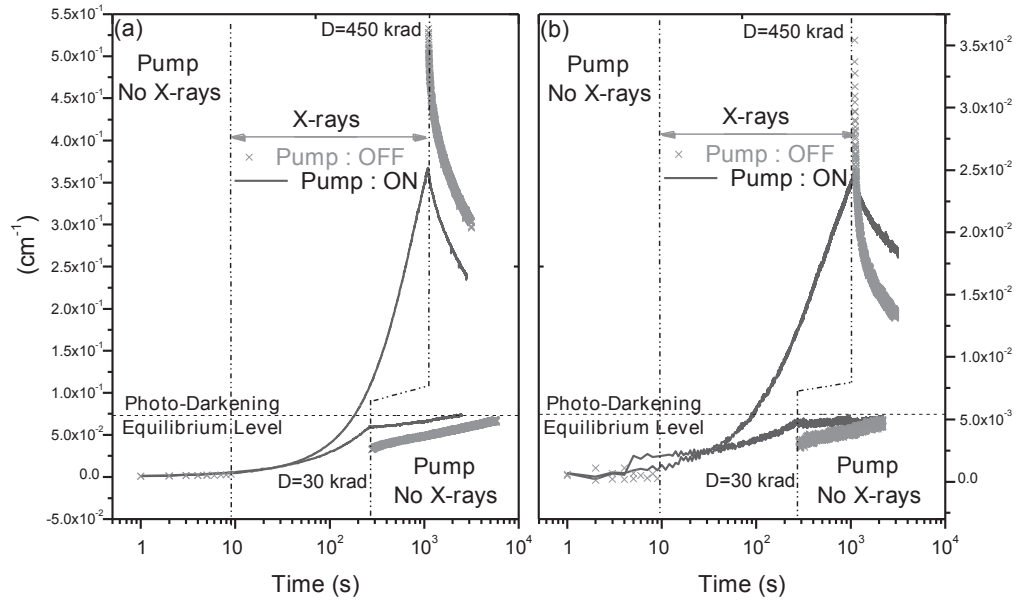

FIGURE 3. Pump effect during PRD. Excess loss $\Delta \alpha$ at $977 \mathrm{~nm}$, for 30 and $450 \mathrm{krad}$ doses, for Al-Yb (a) and Al-Yb-Ce (b).

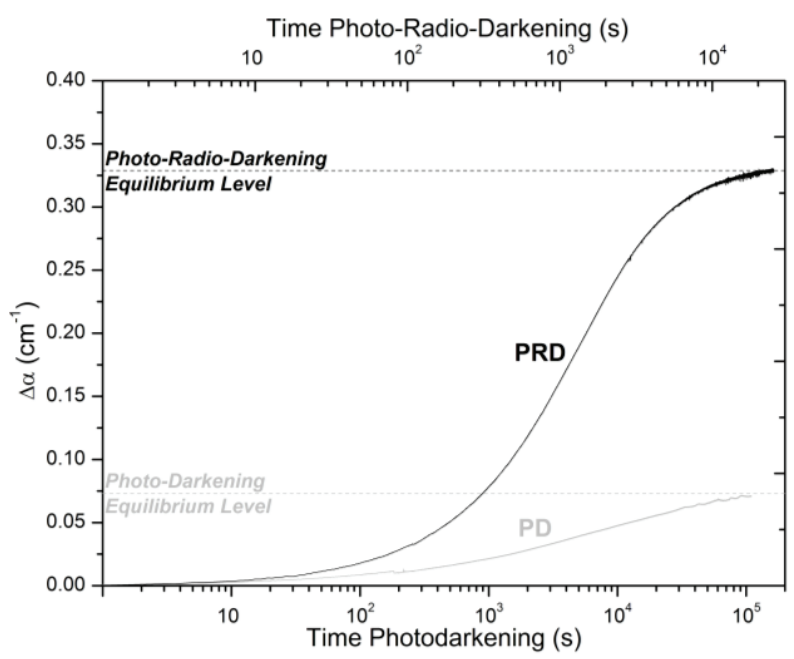

FIGURE 4. Evolution of PD- and PRD (3 Mrad) -induced losses in Al-Yb fiber. 
Decreasing the dose rate will drop this PRD equilibrium closer to the PDEL. In very low dose rate conditions the PRD level will be minimal and equal to the PDEL. Then, the development of RD will be very slow so an "adiabatically" bleaching of the fiber will be ensured by the pump as soon as the PRD level will exceed the PDEL (low level saturation of the PRDEL at the PDEL). To confirm this point, we gave a same high dose (900 krad) to the $\mathrm{Al}-\mathrm{Yb}$ and $\mathrm{Al}-\mathrm{Yb}-\mathrm{Ce}$ fibers, at decreasing mean dose rates. To illustrate $\mathrm{PB}$ by the pump, we did not use lower constant dose rates, but impart the dose in 1, 3 and 6 fractions by observing a 75 min PB time between each fraction. Results are displayed in Fig. 5 and 6 for the Al-Yb and the Al-Yb-Ce fibers respectively. For both fibers, the mean PRD level well tend towards an equilibrium value that decreases with the mean dose rate. We could not reach very low dose rates as those typically encountered in space (too long experiments), but the validated model presented in the work of Mady et al. (this proceeding), which reproduce our experiments, enabled us to extrapolate the observed behaviour to such low dose rates where the PRD is well found to decrease down to the PDEL without passing it. In applications concerned with very low dose rates, as space-based applications $\left(10^{-5}-10^{-3} \mathrm{krad} \mathrm{h}^{-1}\right)$, the PRDEL will be equal to the PDEL.

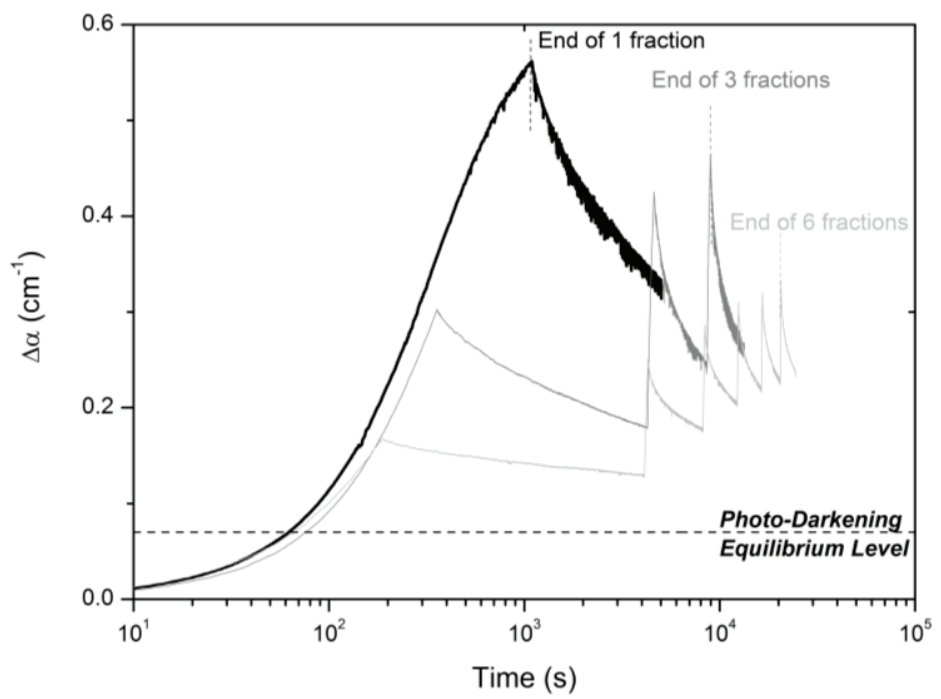

FIGURE 5. Excess loss $\Delta \alpha$ in Al-Yb sample after a $900 \mathrm{krad} \mathrm{X}$-ray dose given in 1.3 and 6 fractions

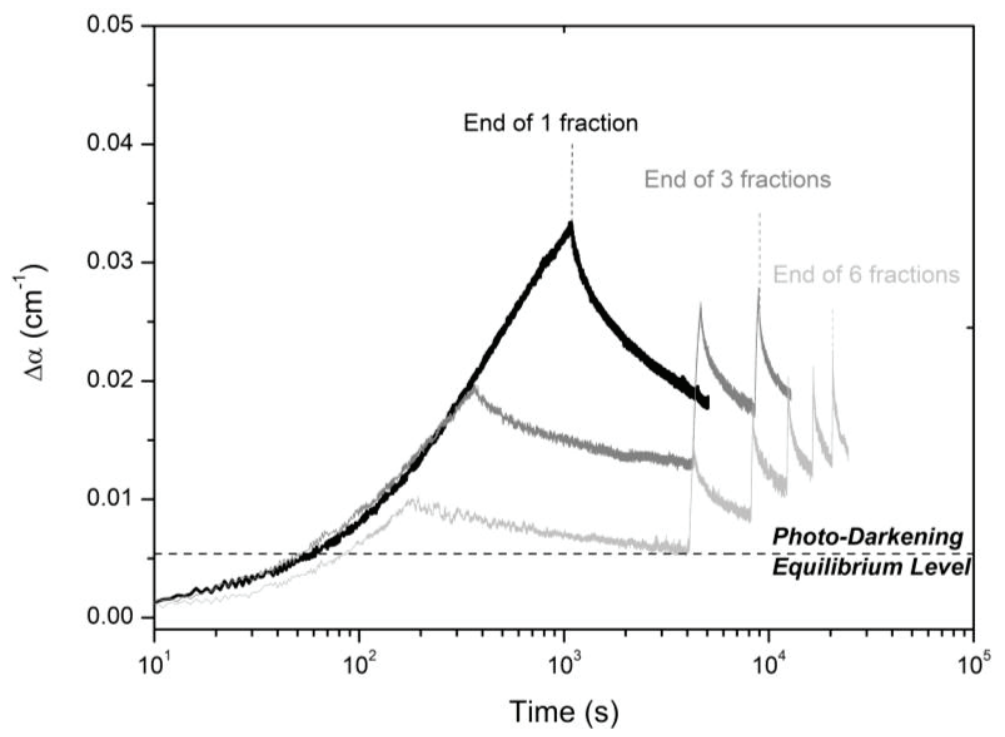

FIGURE 6. Excess loss $\Delta \alpha$ in Al-Yb-Ce sample after a $900 \mathrm{krad} \mathrm{X}$-ray dose given in 1, 3 and 6 fractions. 


\section{DISCUSSION}

PD mitigation can be gained either from the reduction of the efficiency of the pump-induced ionization processes or from the decrease of the capture probability of the free carriers released by such ionization processes on those centers that form color centers upon carrier trapping (introduction of competing trapping centers for instance).

If the PD-hardening recipe results from the latter principle, it should lead to mitigation of RD also, even in the absence of pumping, since the same color centers are shared by PD and RD [11]. This is most probably the case of the COTS Al-Yb-Ce fiber, whose PDEL and RD levels are both reduced by the same factor ( 14) compared with our regular Al-Yb YDF (see Fig. 3). One can consequently suggest that cerium ions serve as trapping centers competing with color center precursors.

If the PD-hardening recipe affects the pump-induced ionization only, the pump will primarily act as a photobleacher of the radiation-induced darkening. Again, this will result in the mitigation of PRD. Such PD-resistant fibers should not be specifically resistant against RD in the absence of pumping ("passive" irradiation). In active (i.e. PRD) conditions, the low PDEL will be rapidly exceeded but a "restoring force" due to the strong PB will attract the PRD down to this low PDEL and the fiber will exhibit a good radio-resistance. Phosphorus (P) or aluminium (Al) co-doped YDF are likely to fall within this category. $\mathrm{P}$ or $\mathrm{Al}[13,14]$ co-doping proved, e.g., to be beneficial against the PD but detrimental to the RD-resistance in the absence of pumping. On one hand, Al-related trapped-hole centers [15] introduce absorption bands that participate in the radiation-induced attenuation (RIA). On the other hand, $\mathrm{Al}$ reduces clustering of $\mathrm{Yb} 3+$ ions and decreases the probability for the cooperative de-excitation of several excited $\mathrm{Yb} 3+$ ions. The latter is though required to release $\mathrm{a}>5 \mathrm{eV}$ energy and produce photo-ionization, e.g. by absorption into the charge transfer (CT) band of $\mathrm{Yb} 3+$ ions (yielding $\mathrm{Yb} 2+$ ions and trapped holes [2]). P-related centers are also formed by carrier trapping [16] and contribute to the RIA, notably in the visible and near infra-red ranges [17]. However, high P concentrations reduce clustering [13] and also shift the Yb3+ charge transfer (CT) band towards higher energies [18]. Both effects dramatically drop the probability of releasing cooperatively a sufficient energy to reach this shifted CT band, hence the photo-ionization rate.

Another way to lessen the darkening losses is to use the properties of PRD by varying the pump power. All experiments described in this paper are performed with the same pump power. But it is well known that an increase of this power in YDF leads to an enhancement of the PDEL. Conversely, the PRDEL decreases when increasing this pump power, due to a better efficiency of the pump induced PB. There is a limit in increasing the pump power: PRDEL and PDEL will merge. If on the contrary the power of the pump is lowered, the PDEL is decreased whereas the PRDEL increases. However, these levels can always come in closer position if the dose rate is decreased. In space, the dose rate is so small $(<10-3$ krad.h-1) that the PRDEL will merge with the PDEL, even if the pump power and the PDEL are low. So if the fiber is PD-resistant, it will be also PRD-resistant in space applications.

\section{CONCLUSION}

We present an original and detailed characterization of YDF pumped in radiative environments. The degradation of fibers submitted to X-rays and pump in the same time, is characterized by the PRDEL, which sets its maximum darkening level. This PRDEL is therefore the relevant reference level to optimize and ensure the fiber resistance against PRD. At very low dose rates, the PRDEL is dropped as low as the PDEL. In these conditions, PD-resistant fibers will exhibit the same resistance against PRD. This statement is true regardless of the dose. It is clear that the radio-resistance of YDF must be tested in actual operating conditions, i.e. under pumping. These outcomes have major consequences on the understanding and assessment of the YDF resistance for applications concerned with PRD. Future work will consist, firstly in the study of degradation kinetic without pumping, to highlight the usefulness of under pumping testing and not only passive testing which may provide opposite trend to our results $[19,20]$. Secondly in a study of other co-doping in YDF like with Al, P, Cerium and in testing of all this fibers in amplifying conditions.

\section{ACKNOWLEDGMENTS}

This work has been funded by the French National Research Agency (ANR) under grant \#11-JS04-007-11. The authors gratefully acknowledge this support. 


\section{REFERENCES}

1 A. Schwuchow, S. Unger, S. Jetschke, and J. Kirchhof, Applied Optics 53, 1466 (2014).

2 M. Engholm, L. Norin, and D. Åberg, Opt. Lett. 32, 3352 (2007).

3 S. Yoo, C. Basu, A. J. Boyland, C. Sones, J. Nilsson, J. K. Sahu, and D. Payne, Opt. Lett. 32, 1626 (2007).

4 S. Jetschke, S. Unger, U. Röpke and J. Kirchhof, Opt. Express 15, 14838 (2007).

5 S. Jetschke, S. Unger, A. Schwuchow, M. Leich, and J. Kirchhof, Opt. Express 16, 15540 (2008).

6 S. Jetschke and U. Röpke, Opt. Lett. 34, 109 (2009).

7 H. Gebavi, S. Taccheo, D. Tregoat, A. Monteville, and T. Robin, Opt. Mater. Express 2, 1286 (2012).

8 S. Rydberg and M. Engholm, Opt. Express 21, 6681 (2013).

9 J. J. Koponen, M. J. Söderlund, S. K. T. Tammela, H. Po, Proc. SPIE 5990, (2005).

10 L. Nanxi, S. Yoo, X. Yu, D. Jain and J.K. Sahu, Photonics Techno. letters, 26, 115, 2014.

11 F. Mady, M. Benabdesselam, and W. Blanc, Opt. Lett. 35, 3542 (2010).

12 S. Girard, Y. Ouerdane, B. Tortech, C. Marcandella, T. Robin, B. Cadier, J. Baggio, P. Paillet, V. FerletCavrois, A. Boukenter, J.-P. Meunier, J. R. Schwank, M. R. Shaneyfelt, P. E. Dodd, and E. W. Blackmore, IEEE Trans. Nucl. Sci. 56, 3293 (2009).

13 T. Deschamps, N. Ollier, H. Vezin, and C. Gonnet, The Journal of Chemical Physics, 136, (2012).

14 A. Kazuo, N. Hiroshi, K. Ken, H. Tatsutoku, I. Yoshiro and H. Takashi, Journal of Applied Physics, 59, 3430 (1986).

15 T. Deschamps, H. Vezin, C. Gonnet, and N. Ollier, Opt. Express 21, 8382 (2013).

16 D. L. Griscom, E. J. Friebele, K. J. Long and J. W. Fleming, Journal of Applied Physics, 54, 3743 (1983).

17 S. Girard, C. Marcandella, A. Morana, J. Perisse, D. Di Francesca, P. Paillet, J.-R. Mace, A. Boukenter, M. Leon, M. Gaillardin, N. Richard, M. Raine, S. Agnello, M. Cannas and Y. Ouerdane, TNS 4305 ( 2013).

18 M. Engholm and L. Norin, Opt. Express 16, 1260 (2008).

19 F. Mady, M. Benabdesselam, J.-B. Duchez, Y. Mebrouk and S. Girard, IEEE T. Nucl. Sci. 60, 4341 (2013).

20 O. Gilard, J. Thomas, L. Troussellier, M. Myara, P. Signoret, E. Burov and M. Sotom, Appl. Opt. 51, 2230 (2012). 